\title{
Adult-onset linear discoid lupus erythematosus on the forehead mimicking en coup de sabre: a case report
}

\author{
Sasipaka Sindhusen, Kumutnart Chanprapaph and Suthinee Rutnin ${ }^{*}$ (1)
}

\begin{abstract}
Background: Linear cutaneous lupus erythematosus (LE) is an unusual form of LE-specific cutaneous condition, occurring in children and young adults. Due to its rarity, the diagnosis of linear cutaneous LE can be difficult and facial lesions can resemble linear morphea or en coup de sabre. Differential diagnosis of similar conditions along the lines of Blaschko must be differentiated from linear LE.

Case presentation: We report a case of linear discoid LE on the forehead of an adult female Thai patient mimicking en coup de sabre. The dermatoscopy, histopathology and direct immunofluorescence findings were consistent with chronic cutaneous LE.

Conclusions: As this patient demonstrated classic dermatoscopic features of $L E$, we emphasized that the diagnosis of linear cutaneous LE can be made by dermatoscopy. This is particularly beneficial for young self-conscious patients with facial lesions that are reluctant to perform skin biopsy.
\end{abstract}

Keywords: Linear lupus erythematosus, Discoid lupus erythematosus, En coup de sabre, Linear morphea, Blaschko line

\section{Background}

Lupus erythematosus (LE) is an autoimmune connective tissue disease characterized by a heterogenous spectrum of skin and internal organ manifestations. Linear discoid lupus erythematosus (LDLE) is a rare variant of DLE characterized by linear erythematous plaques along the lines of Blaschko. Differential diagnosis must be considered with other linear conditions. Due to its rarity, histopathological examination is mainly required to establish the definitive diagnosis. According to Lallas et al. [1], dermatoscopy may enhance the clinical diagnosis of DLE especially in the patient who cannot perform a skin biopsy. We hereby report DLE in an adult patient presenting with a linear variant on the forehead clinically mimicking en coup de sabre. We emphasize that the characteristic dermatoscopic findings including structureless whitish areas, follicular keratotic plugs, telangiectatic vessels and brown to grayish pigmentation are

\footnotetext{
* Correspondence: suthinee.rutnin@gmail.com

Division of Dermatology, Department of Medicine, Ramathibodi Hospital, Mahidol University, 270 Rama VI Road, Ratchatewi, Bangkok 10400, Thailand
}

of great value in differentiating DLE from other linear conditions distributed along the lines of Blaschko.

\section{Case presentation}

A 28-year-old Thai office worker from Bangkok presented with a 3-month history of an asymptomatic linear erythematous to purplish atrophic patch on the forehead following the lines of Blaschko (Fig. 1). She had no history of trauma preceding the lesions or photosensitivity. She had no underlying disease or family history of malignancy or other autoimmune connective tissue diseases. She is an only daughter living with her family that belongs to middle socioeconomic class. Her menstrual cycle was normal. She had no history of smoking or alcoholic consumption. She was previously treated at a provincial hospital with mometasone furoate cream $0.1 \%$ once daily for 3 weeks but the lesion did not improve. On physical examination, her temperature was $36.7^{\circ} \mathrm{C}$, blood pressure $119 / 83 \mathrm{mmHg}$, pulse rate $100 /$ minute and respiratory rate 20/minute. Cardiovascular and respiratory assessments were normal. Neurological examination showed all intact cranial nerves. Motor and

(c) The Author(s). 2019 Open Access This article is distributed under the terms of the Creative Commons Attribution 4.0 International License (http://creativecommons.org/licenses/by/4.0/), which permits unrestricted use, distribution, and 


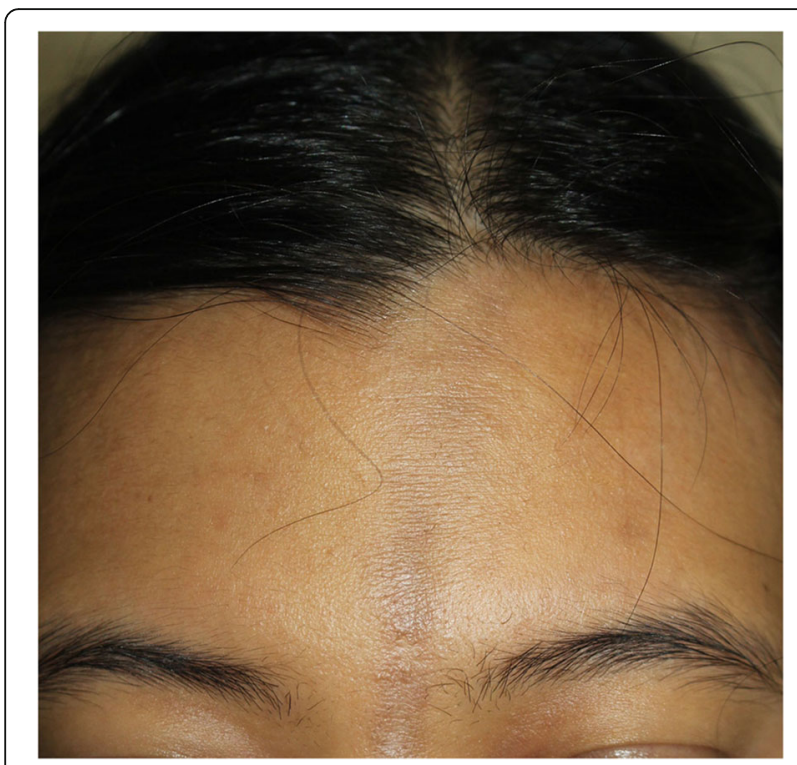

Fig. 1 Linear erythematous to purplish atrophic patch on the forehead

sensory examinations were within normal limits. Other dermatological examinations were unremarkable including mucous membranes, scalp, hair and nails. The initial diagnosis was en coup de sabre. Dermatoscopic evaluation demonstrated structureless whitish areas, follicular keratotic plugs, telangiectatic vessels and brown to grayish pigmentation (Fig. 2), which are reminiscent of DLE. Therefore, after obtaining inform consent, a skin biopsy specimen from the forehead was performed and revealed epidermal atrophy, follicular plugging, and hydropic degeneration of the basal cell layer. Superficial and deep perivascular and periadnexal lymphocytic infiltrate with numerous melanophages, telangiectasia, and dermal

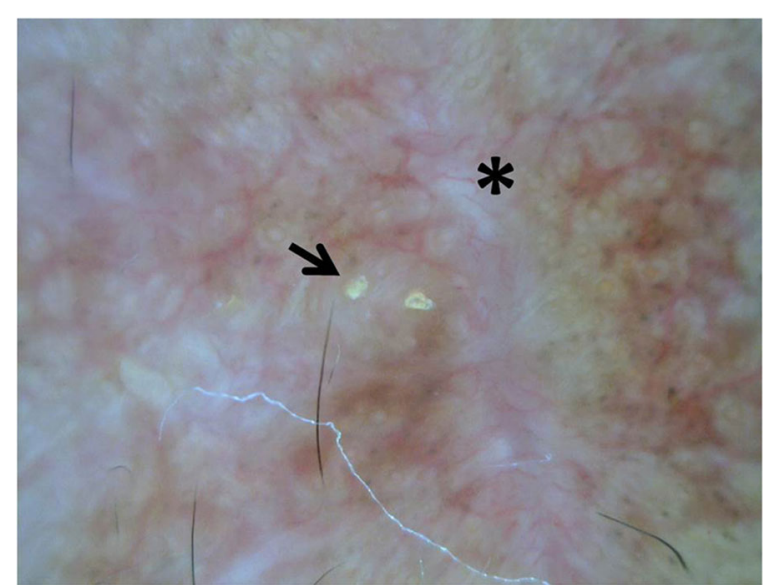

Fig. 2 Dermatoscopy demonstrated structureless whitish areas (asterisk), follicular keratotic plugs (arrow), telangiectatic vessels and brown to grayish pigmentation (original magnification $\times 50$ ) fibrosis (Fig. 3). Direct immunofluorescence (DIF) of a lesional skin revealed homogeneous granular deposition of immunoglobulin $\mathrm{M}$ (IgM) along the dermoepidermal junction and follicular epithelium with few cytoid bodies of IgM (Fig. 4). Her complete blood count (CBC) showed hemoglobin $(\mathrm{Hb})$ level of $13.4 \mathrm{~g} / \mathrm{dL}$, white blood cell (WBC) count of $6.3 \times 10^{9} / \mathrm{L}$ composing of $69 \%$ neutrophils, $26 \%$ lymphocytes, and 5\% monocytes, and platelet count of $233 \times 10^{9} / \mathrm{L}$. Liver function test (LFT) revealed total and direct bilirubin levels of $0.4 \mathrm{mg} / \mathrm{dL}$ and $0.2 \mathrm{mg} /$ $\mathrm{dL}$, respectively, aspartate aminotransferase (AST) $18 \mathrm{IU} /$ L, alanine aminotransferase (ALT) $11 \mathrm{IU} / \mathrm{L}$, alkaline phosphatase (ALP) 44IU/L, and gamma-glutamyl transferase (GGT) 13 IU/L. She had negative hepatitis B virus surface antigen (HBsAg) and anti-hepatitis $\mathrm{C}$ virus (anti-HCV) in her serum. Renal function test showed blood urea nitrogen (BUN) of $9 \mathrm{mg} / \mathrm{dL}$ and creatinine of $0.6 \mathrm{mg} / \mathrm{dL}$. No proteinuria was observed and there were $0-1$ white blood cells and red blood cells /high power field in urinalysis. Antinuclear antibody titer was negative. Based on the clinical and dermatoscopic examinations, histological and DIF results, the diagnosis of linear DLE was made. Tacrolimus ointment $0.1 \%$ was applied twice daily on the lesion alongside with hydroxychloroquine $(200 \mathrm{mg} /$ day $)$. Strict sun protection was also advised. At 6-month follow-up, the lesions showed significant improvement and resolved with atrophic patch.

\section{Discussion}

We report a case of linear discoid LE on the forehead of an adult female patient mimicking en coup de sabre. To the best of our knowledge, this is the first case emphasizing on the characteristic dermatoscopic findings of LDLE on the forehead which are important information in differentiating DLE from other linear conditions distributed along the lines of Blaschko.

Cutaneous LE (CLE) presenting with linear configuration is exceeding rare. A linear variant of CLE was first described in 1978 by Umbert and Winklemann [2] as a cutaneous mixed or overlap syndrome between linear scleroderma and DLE. Later in 1998, Abe et al. [3] reported 2 cases of linear childhood CLE following the line of Blashko and proposed the term linear cutaneous lupus erythematosus (LCLE) to described this rare variant of CLE.

According to the literature review, a total of 102 cases diagnosed with LCLE have been reported. The most common pathological diagnosis of CLE in the linear distribution was discoid lupus erythematosus (DLE) (39.2\%), followed by lupus erythematosus panniculitis (LEP) (21.6\%), lupus erythematosus tumid (LET) (2.9\%), subacute lupus erythematosus (SCLE) (2\%) and bullous lesions of SLE (1\%) [4-13]. LDLE mainly occurs in children and young adults. The mean age onset was 22.1 years (1-68 years). Unlike the female predominance 


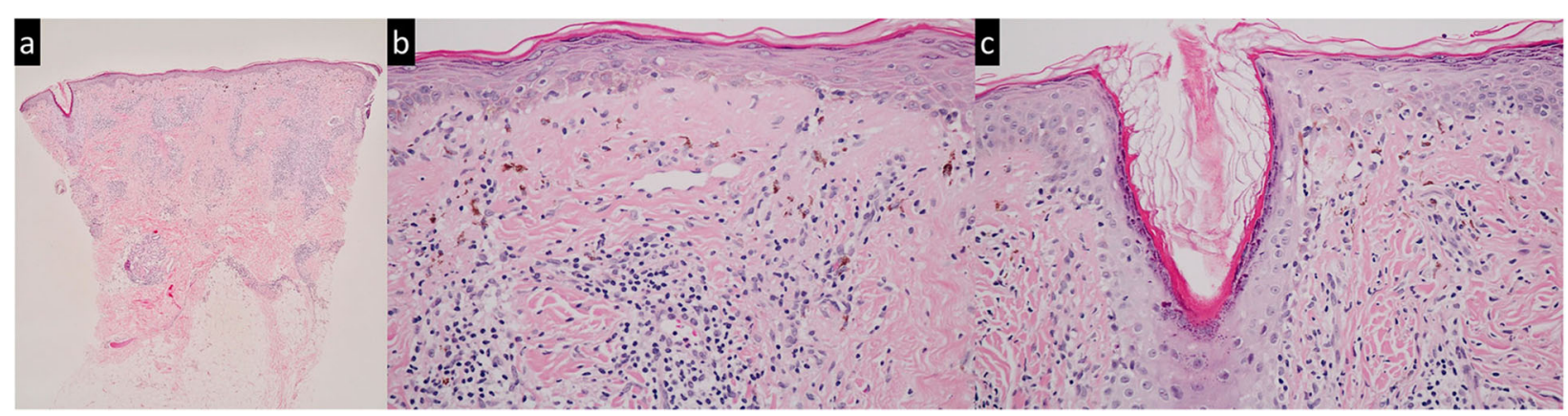

Fig. 3 Histopathology of linear discoid lupus erythematosus (a) superficial and deep perivascular and periadnexal lymphocytic infiltrate (haematoxylin and eosin stain, original magnification $\times 40)(\mathbf{b})$ epidermal atrophy, hydropic degeneration of the basal cell layer, numerous melanophages, and telangiectasia (haematoxylin and eosin stain, original magnification $\times 400)($ c) follicular interface change with follicular hyperkeratosis (haematoxylin and eosin stain, original magnification $\times 400$ )

typically seen in SLE patients, no gender predilection was noted in LCLE with female to male ratio of 1.3:1. The typical clinical manifestations were single or multiple linear asymptomatic erythematous plaques along the lines of Blaschko. Lesions developed most commonly on head followed by neck, trunk, and extremities. There have been only 9 reported cases of adult-onset linear CLE on the forehead which could be mistaken for en coup de sabre (Table 1). LE-associated serology such as the antinuclear antibodies are mostly negative. Photosensitivity and progression to SLE are rarely observed [7, 9, 10].

The exact pathogenesis of LCLE is unknown. Alfred Blaschko first described the lines of Blaschko in 1901 and represent the developmental growth pattern of the embryonic ectodermal cells. In the linear variant of CLE, genetic mosaicism/epigenetic modification of keratinocytes and the immune system in the lines of Blaschko may play a potential role in development of this specific CLE variant [7, 14]. The keratinocytes in the lines of Blaschko triggered by trauma, irritation, or ultraviolet light may express antigens and introduce a wide range of stimuli crucial for the development of CLE. Keratinocyte apoptosis has also been indicated as a key event in initiating CLE through various apoptotic pathway such as p53, tumor necrosis factor alpha (TNF- $\alpha$ ), and Fas/ Fas Ligand (FasL). However, it remains a speculation whether these genetically variant keratinocytes are indeed lacking proteins essential for regulation of apoptosis, are there immunological distinct showing aberrant major histocompatibility complex (MHC) expression, or are there relaxing abnormal aberrant cytokines [7, 14].

The differential diagnosis of LCLE includes other acquired inflammatory skin diseases distributed along the lines of Blaschko, such as linear morphea, linear lichen planus, lichen striatus, linear psoriasis, linear lichen sclerosus and linear granuloma annulare [10].

Although, the final diagnosis of CLE was achieved by histopathological examination, dermatoscopic findings also play an important role to identify the accurate diagnosis. Lallas et al. described the dermatoscopic criteria of DLE located on the face, trunk and extremities, and correlated them to the underlying histopathology. Perifollicular whitish halo, follicular keratotic plugs and telangiectasia were the most common dematoscopic findings in DLE [1].

In our patient, some dermatoscopic features correspond well to the histopathological findings. Dermatoscopic findings showed follicular keratotic plugs,

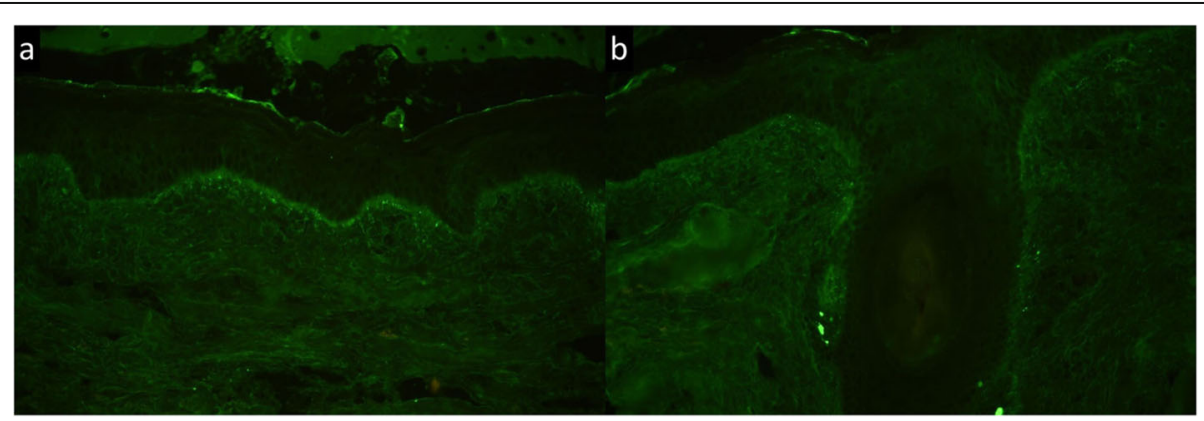

Fig. 4 Direct immunofluorescence showed homogenous granular deposition of IgM and few cytoid bodies along the basement membrane (a) and follicular epithelium $(\mathbf{b})$ (original magnification $\times 400$ ) 
Table 1 Summary of previous reported cases of adult-onset linear cutaneous lupus erythematosus on the forehead [7]

\begin{tabular}{|c|c|c|c|c|c|c|c|c|c|c|}
\hline No. & Sex & Age of onset & Duration & Location & $\begin{array}{l}\text { Pathological } \\
\text { diagnosis }\end{array}$ & DIF & ANA & Other autoantibodies & $\begin{array}{l}\text { Progression } \\
\text { to SLE }\end{array}$ & Treatment \\
\hline 1 & $\mathrm{~F}$ & $29 y$ & $3 y$ & Forehead & CLE & $\begin{array}{l}\text { +Granular } \\
\text { IgM }\end{array}$ & - & NA & No & $\mathrm{TC}, \mathrm{HCQ}$ \\
\hline 2 & F & $21 \mathrm{y}$ & Few $\mathrm{m}$ & Forehead, scalp & LET & NA & $\begin{array}{l}9 y \\
\text { later: } \\
\text { +ANA }\end{array}$ & 9 y later: +anti-dsDNA, +RF & Yes & $\begin{array}{l}\text { ILC } \\
9 \text { y later: } \\
\text { IC, OC, } \\
\text { CTX, HCQ }\end{array}$ \\
\hline 3 & M & $49 y$ & $1 \mathrm{y}$ & $\begin{array}{l}\text { Forehead, inner eye } \\
\text { angle, right lateral } \\
\text { aspect of nose }\end{array}$ & CCLE & $\begin{array}{l}\text { +Band-like } \\
\text { lgG, IgM, } \\
\lg A, C 3\end{array}$ & - & NA & No & $\mathrm{HCQ}$ \\
\hline 4 & M & $21 \mathrm{y}$ & $1 \mathrm{y}$ & $\begin{array}{l}\text { Forehead, left } \\
\text { supraorbital and } \\
\text { infraorbital area, left } \\
\text { angle of mouth }\end{array}$ & CLE & + & - & $\begin{array}{l}+ \text { Anti-SSA, } \\
+ \text { anti-SSB }\end{array}$ & No & $\begin{array}{l}\mathrm{HCQ}, \mathrm{TC} \\
\mathrm{TCl}\end{array}$ \\
\hline 5 & M & 33 y & $1 \mathrm{y}$ & Forehead & $\mathrm{CCLE}, \mathrm{SCl}$ & $\begin{array}{l}\text { +Granular } \\
\text { lgM }\end{array}$ & - & $\begin{array}{l}\text {-Anti-RNP, } \\
\text {-anti-NCS, } \\
\text {-anti-dsDNA }\end{array}$ & No & $\begin{array}{l}\mathrm{CQ}, \mathrm{TC} \\
\mathrm{TCl}\end{array}$ \\
\hline 6 & M & 33 y & $2 m$ & $\begin{array}{l}\text { Forehead, left eyelid, } \\
\text { nose }\end{array}$ & CLE & NA & - & NA & No & $\mathrm{HCQ}, \mathrm{TC}$ \\
\hline 7 & $\mathrm{~F}$ & $24 y$ & $2 y$ & Forehead, scalp & LEP & $\begin{array}{l}\text { +Granular } \\
\text { lgG }\end{array}$ & + ANA & $\begin{array}{l}\text { +Anti-SSA } \\
\text {-anti-dsDNA, } \\
\text {-anti-ssDNA, } \\
\text {-anti-Sm, } \\
\text {-anti-SSB }\end{array}$ & No & OC \\
\hline 8 & M & $42 y$ & $1 \mathrm{y}$ & $\begin{array}{l}\text { Forehead, right upper } \\
\text { eyelid }\end{array}$ & LET & $\begin{array}{l}\text { +Granular } \\
\text { IgM, C3 }\end{array}$ & - & NA & No & $\mathrm{OC}, \mathrm{HCQ}$ \\
\hline 9 & $\mathrm{~F}$ & $24 y$ & $8 y$ & $\begin{array}{l}\text { Forehead, scalp, left } \\
\text { cheek }\end{array}$ & DLE, Scl & NA & NA & NA & No & $\begin{array}{l}\mathrm{OC}, \mathrm{CQ}, \\
\mathrm{TC}, \mathrm{TCl}\end{array}$ \\
\hline
\end{tabular}

Abbreviations: ANA, anti-nuclear antibodies; anti-dsDNA, anti-double stranded DNA; anti-NCS, antinucleosome; anti-RNP, anti-ribonucleoprotein; anti-Sm, antiSmith; anti-ssDNA, anti-single stranded DNA; C3, complement C3; CCLE, chronic cutaneous lupus erythematosus; CLE, cutaneous lupus erythematosus; CQ, chloroquine; CTX, cyclophosphamide; DIF, direct immunofluorescence; DLE, discoid lupus erythematosus; F, female; HCQ, hydroxychloroquine; IC, Intravenous corticosteroid; IgA, immunoglobulin A; IgG, immunoglobulin G; IgM, immunoglobulin M; ILC, intralesional injection of corticosteroid; LEP, lupus erythematosus panniculitis; LET, lupus erythematosus tumid; M, male; m, month; NA, Not available; No., number; OC, oral corticosteroid; RF, rheumatoid factor; Scl, scleroderma; SLE, systemic lupus erythematosus; TC, topical corticosteroid; TCl, topical calcineurin inhibitors; y, year

telangiectatic vessels, pigmentation, and structureless whitish areas, representing histopathologic features of follicular hyperkearatosis, telangiectasia, pigmentary incontinence, and diffuse dermal fibrosis, respectively. In addition to dematoscopic and histopathologic diagnosis, direct immunofluorescence (DIF) of lesional skin is also the useful adjunction for diagnosing LDLE. These findings are granular depositions of IgG, IgM, IgA, and/or C3 along the dermoepidermal junction and periadnexal structure. Nonetheless, a negative DIF result does not exclude the diagnosis [10].

In linear DLE, topical high-potency corticosteroids and photoprotection are the mainstay of therapy [15]. Topical calcineurin inhibitors are reserved for long-term maintenance [16]. In cases presenting with widespread lesions unresponsive to topical therapy, antimalarials especially hydroxychloroquine may be considered as the first-line drug. Other systemic treatments including oral corticosteroids, dapsone, thalidomide, mycophenolate mofeti, azathioprine and retinoids have been reported to be benificial [16].

\section{Conclusions}

We hereby reported a case of adult-onset LDLE presented with linear erythematous to purplish atrophic patch on the forehead along the lines of Blaschko masquerading en coup de sabre. We would like to encourage physicians to use dermatoscopy to establish a clinical diagnosis, particularly in young selfconscious patients with facial lesions and are hesitant to perform skin biopsy.

\section{Acknowledgements \\ We acknowledge the assistance of Dr. Poonkiat Suchonwanit in the preparation of illustrations.}

\section{Authors' contributions}

SS drafted the manuscript. KC and SR revised the manuscript critically for intellectual content. All authors read and approved the final manuscript.

Funding

None.

Availability of data and materials

Please contact the authors for data requests.

Ethics approval and consent to participate

The patient was informed and gave her inform consent. 


\section{Consent for publication}

Written informed consent was obtained from the patient for publication of this case report and any accompanying images. A copy of the written consent is available for review by the Editor-in-Chief of this journal.

\section{Competing interests}

The authors declare that they have no competing interests.

Received: 9 July 2019 Accepted: 2 September 2019

Published online: 27 November 2019

\section{References}

1. Lallas A, Apalla Z, Lefaki I, Sotiriou E, Lazaridou E, loannides D, et al. Dermoscopy of discoid lupus erythematosus. $\mathrm{Br} J$ Dermatol. 2013:168(2):284-8.

2. Umbert $P$, Winkelmann RK. Concurrent localized scleroderma and discoid lupus erythematosus. Cutaneous 'mixed' or 'overlap' syndrome. Arch Dermatol. 1978;114(10):1473-8.

3. Abe M, Ishikawa O, Miyachi Y. Linear cutaneous lupus erythematosus following the lines of Blaschko. Br J Dermatol. 1998;139(2):307-10.

4. Bernardez C, Prieto-Torres $L$, Macias E, Ramirez-Bellver JL, Haro-Ramos R, Diaz-Recuero $\mathrm{JL}$, et al. Concurrent presentation of cutaneous lesions of deep linear morphoea and discoid lupus erythematosus. Lupus. 2016;25(2):204-8.

5. Campos-Munoz L, Fueyo-Casado A, Conde-Taboada A, Carranza-Romero C, Lopez-Bran E. Clinical Images: Progressive linear blaschkoid lupus erythematosus. Arthritis Rheumatol. 2017:69(11):2250.

6. Elbendary A, Griffin J, Li S, Tlougan B, Junkins-Hopkins JM. Linear Sclerodermoid Lupus Erythematosus Profundus in a Child. Am J Dermatopathol. 2016;38(12):904-9.

7. Jin H, Zhang G, Zhou Y, Chang C, Lu Q. Old lines tell new tales: Blaschko linear lupus erythematosis. Autoimmun Rev. 2016;15(4):291-306.

8. Lueangarun S, Subpayasarn U, Chakavittumrong P, Tempark T, Suthiwartnarueput W. Lupus panniculitis of the scalp presenting with linear alopecia along the lines of Blaschko. Clin Exp Dermatol. 2017;42(6):705-7.

9. Mao QX, Zhang WL, Wang Q, Xiao XM, Chen H, Shao XB, et al. Linear cutaneous lupus erythematosus/discoid lupus erythematosus in an adult. Postepy Dermatol Alergol. 2017;34(2):177-9.

10. Marinho AK, Ramos TB, Barbosa DM, Kozmhinsky V, Takano DM, Figueira MM. Linear cutaneous lupus erythematosus following the lines of Blaschko Case report. An Bras Dermatol. 2016;91(4):510-3.

11. Meena M, Balai M, Mehta S, Bharti G. Chronic Cutaneous Lupus Erythematosus in a Blaschkoid Pattern over Face. Indian J Dermatol. 2018;63(2):180-1.

12. Ogawa M, Muro Y, Sugiura K, Sakakibara A, Akiyama M. Magnetic resonance imaging findings are useful for evaluating the three-dimensional development and follow-up of linear lupus erythematosus profundus. Lupus. 2015;24(11):1214-6.

13. Saha A, Seth J, Pradhan S, Dattaroy S. Disseminated discoid lupus erythematosus with a linear lesion on the forearm and hand: A rare presentation and review of literature. Indian J Dermatol Venereol Leprol. 2017;83(5):586-9

14. Seitz CS, Brocker EB, Trautmann A. Linear variant of chronic cutaneous lupus erythematosus: a clue for the pathogenesis of chronic cutaneous lupus erythematosus? Lupus. 2008;17(12):1136-9.

15. Devaraj NK, Aneesa AR, Abdul AH, Shaira N. Topical corticosteroids in clinical practice. Med J Malaysia. 2019;74(2):187-9.

16. Okon LG, Werth VP. Cutaneous lupus erythematosus: diagnosis and treatment. Best Pract Res Clin Rheumatol. 2013;27(3):391-404.

\section{Publisher's Note}

Springer Nature remains neutral with regard to jurisdictional claims in published maps and institutional affiliations.

Ready to submit your research? Choose BMC and benefit from:

- fast, convenient online submission

- thorough peer review by experienced researchers in your field

- rapid publication on acceptance

- support for research data, including large and complex data types

- gold Open Access which fosters wider collaboration and increased citations

- maximum visibility for your research: over $100 \mathrm{M}$ website views per year

At BMC, research is always in progress.

Learn more biomedcentral.com/submissions 